\title{
Towards Machine Independence: from Mechanically Programmed Devices to the Internet of Things
}

\author{
Arthur Tatnall $^{1}$ and Bill Davey ${ }^{2}$ \\ ${ }^{1}$ Victoria University, Melbourne, Australia, ${ }^{2}$ RMIT University, Melbourne, Australia \\ Arthur.Tatnall@vu.edu.au, Bill.Davey@rmit.edu.au
}

\begin{abstract}
This is an historical account of the development of an aspect of technology and of machines, leading to information technologies, the Internet and the Internet of Things. It points to an increasing trend towards these machines and devices becoming more and more independent of human intervention and control. We have not quite got there yet, but a clear trend can be observed nevertheless from mechanically controlled machines such as $\mathrm{Al}$ Jazari's Castle Clock which a naïve $13^{\text {th }}$ century observer could have thought had a life of its own to modern smart kitchen and household appliances (from the Internet of Things) that really could be said to have a degree of independence. The paper makes use of actor-network theory as a lens for understanding the human and non-human elements of this historical trend.
\end{abstract}

Keywords: Machines, technology, information technology, independence, human operating, control, Internet, Internet of Things, artificial intelligence, science fiction, Actor-Network Theory

\section{Introduction}

This paper examines a trend in the history of technology - the gradual path towards machines that require little or no human intervention to operate, that is, towards independent machines. In this paper the term 'independent' is related to human independence. A human grows through stages from a totally dependent baby to a largely independent adult. We identify four aspects that identify this growth:

- The ability to control one's life

- The ability to operate without aid in the world

- 'Self-maintenance'

- The ability to decide the direction that one's life might take.

Of course independent humans are constrained by their 'manufacture' (size, strength, intelligence, appearance and genetics), by their environment and available resources and by their 'programming' (their culture, value system and education). In this way we consider the trend of machines towards a type of independence, perhaps constrained by a set of 'values' like Asimov's three laws of robotics [1] and by their 
manufacture. We ask: can a machine capable of fulfilling these characteristics be seen as human independent?

In this somewhat light hearted and rather speculative paper, but one with a serious point, we will make use of some concepts and scenarios from science fiction to look at interactions between humans and non-human technologies, where humans can be marginalised, or even replaced by these technologies, as well as the use of regular research references and factual material. Where will the relationship between these technologies and humans lead in the future as these machines become more independent? In the paper we will use actor-network theory (ANT) to look at how networks of humans and non-humans (machines) and their interactions may change as the machines gain a greater degree of autonomy.

The paper uses examples of various technologies ${ }^{1}$ to show an historical trend towards machines capable of self-operation, self-control and self-maintenance, and machines potentially able to set their own agendas and purposes. It begins with mechanically programmed devices such as court automata from the $10^{\text {th }}$ century intended to inspire amusement and awe [2], continues through various items of computing technology and the Internet and ends with the Internet of Things.

\section{Machine Independence}

Before going much further though we should define the terms: 'machine' and 'independence' and look at how they might be related.

- A machine is: "a tool containing one or more parts that uses energy to perform an intended action." [3]

- Independence can be defined as: "Free from outside control; not subject to another's authority" and "Capable of acting or thinking for oneself" [4]. Another definition adds: "Not subject to control by others" [5].

So we can say then that for it to be independent, a device, be it an item of technology or a machine, must be free from outside influence or control and capable of acting or 'thinking' for itself. We will consider the following factors:

- Power source - is this independent of the human user or of the machine itself?

- Operation - how is the machine operated? Does it need a human or can it operate itself?

- Mechanism for control of underlying behaviour - what determines how the machine is controlled and what tasks it performs? Does this need direct human intervention?

- Maintenance - to what extent can the machine look after its own needs?

To take an example, windmills and water wheels can operate (though perhaps not usefully) without direct human intervention once set up, but a steam train requires a

1 Although there are significant differences between machines and technologies in some contexts, in this paper we will often use these two terms to refer mainly to machines. 
human constantly shovelling coal in order to operate. A solar cell, once set up, does operate independently.

In the case of a very early machine - a horse and cart, the horse was the power source but the operation and control were human. The horse and cart could perform no useful task without the human driver. A Model T Ford needed a human operator to drive and to control its operation having, as distinct from a modern car, few of its own mechanisms for underlying control. All cars nowadays have anti-lock braking systems which operate without direct human intervention. Cars that can park themselves are now common and driverless cars are beginning to appear. Cars are gaining a good degree of independence from human control. Passenger jet aircraft now all have an autopilot that, whilst in operation makes the plane completely human independent.

\section{Early Automated Devices - Mechanically Programmed Robots}

There are many early examples of automation intended for amusement and awe rather than with some practical function. An early example was a mechanical theatre that performed a play, almost ten minutes in length, invented by Hero of Alexandria (c10-70 AD) and powered by a complex system of ropes and machines operated by a rotating cylindrical cogwheel that produced the sound of thunder by use of metal balls dropped onto a hidden drum and mechanically-timed [2]. It could be argued that this involved an early example of programming [6]. Another early example appears in the way that a $10^{\text {th }}$ century Byzantine emperor impressed barbarians at his court by the presence of automata including lions roaring on either side of his throne, and birds resting on the surrounding trees singing harmoniously [2]. To the naïve observer in his court these would have been seen as rather magical and to have been

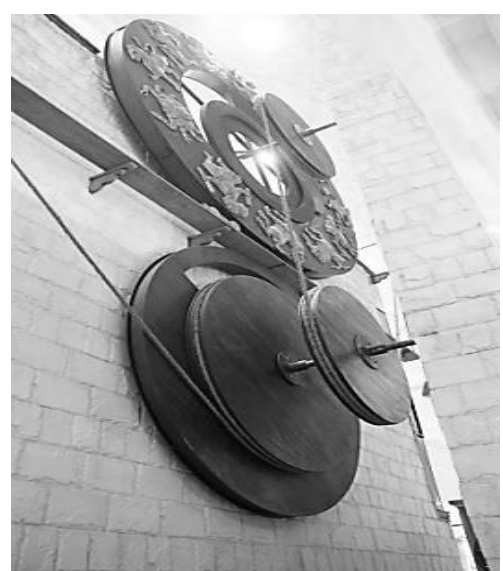

Fig. 1. Castle Clock mechanism operating independently.

In the early $13^{\text {th }}$ century, Muslim engineer Ismail Al-Jazari described various types of automated devices and robots [7], one of the most famous being the Castle Clock which was a complex device that had multiple functions besides keeping the time. It also displayed the zodiac, solar and lunar orbits, and a crescent moon shaped pointer that was moved by a hidden cart and caused doors to open every hour to show mechanical musicians playing their instruments [6]. It also allowed for reprogramming the length of day and night to compensate for changes throughout the year. 


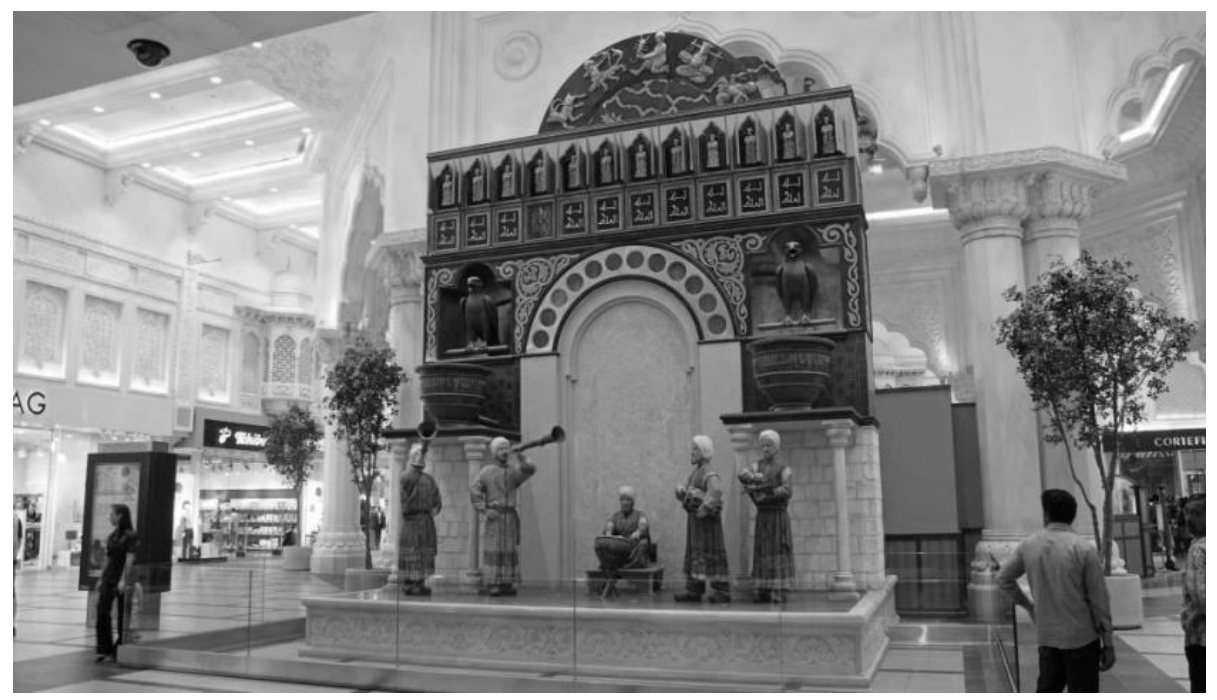

Fig. 2. Castle Clock. This is a reconstruction of the clock by Al-Jazari [7] (in Ibn Battuta Mall, Dubai) from his 'Book of Knowledge of Ingenious Mechanical Devices'.

In Europe from the middle ages there are many more examples of automata, including a number of mechanical astronomical clocks that began to appear in the $14^{\text {th }}$ century.
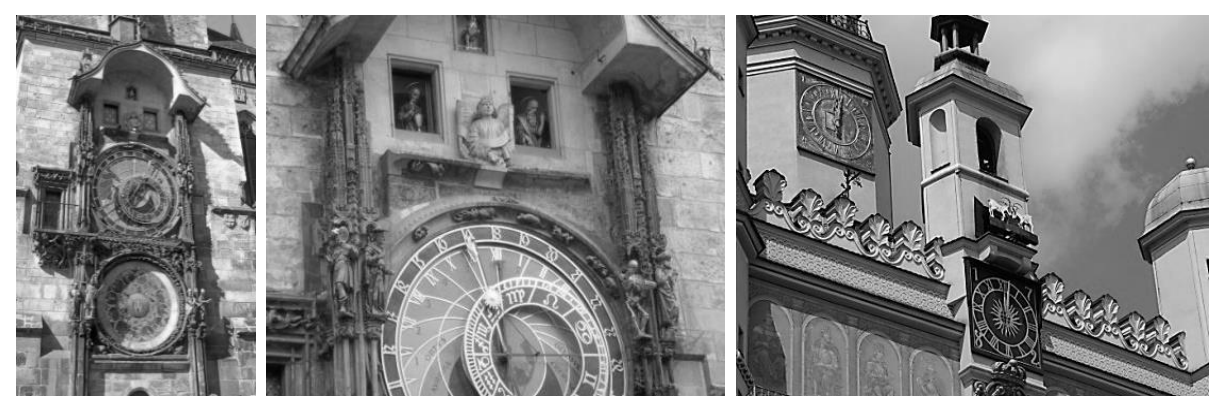

Fig. 3. Astronomical Clocks: Prague (Czech Republic) and Poznań Goats (Poland)

\section{Robots, Artificial Intelligence and Science Fiction}

Karel Čapek [8] is credited with originating use of the word 'robot' in his play: 'Rossum's Universal Robots' in which the demise of humans through a robot revolution is unleashed. Another story: 'Do Androids Dream of Electric Sheep?' [9] also introduces a dark side of robotics. To make a machine more independent, some form of artificial intelligence needs to come into the picture. John McCarthy et al. [10] first defined Artificial Intelligence in 1955 as: "the science and engineering of making intelligent machines", but in a recent BBC broadcast [11], Professor Stephen Hawking suggested that: "The development of full artificial intelligence could spell the end of the human race". Hawking fears the consequences of creating something 
that is able to match or surpass humans. "It would take off on its own, and re-design itself at an ever increasing rate. Humans, who are limited by slow biological evolution, couldn't compete, and would be superseded." [11]. This change could produce a fundamentally different type of technology that can be seriously compared with the science fiction scenarios involving self-aware artificial intelligences [12]. In an example from science fiction, the artificial intelligence possessed by HAL, the ship-board computer in '2001: A Space Odyssey', meant that it could prevent a crew member from taking an action it considered to be detrimental: "I'm sorry, Dave. I'm afraid I can't do that. ... This mission is too important for me to allow you to jeopardize it."

We now ask the question: can robots be independent? Beginning with more science fiction examples, 'Star Wars' robots R2D2 and C3PO were certainly able to act with a fair degree of independence while the actions of the Terminator were certainly independent of human control. Marvin the paranoid android from 'The Hitch-Hikers Guide to the Galaxy' [13] and the inside doors of the 'Heart of Gold spaceship' also had personalities.

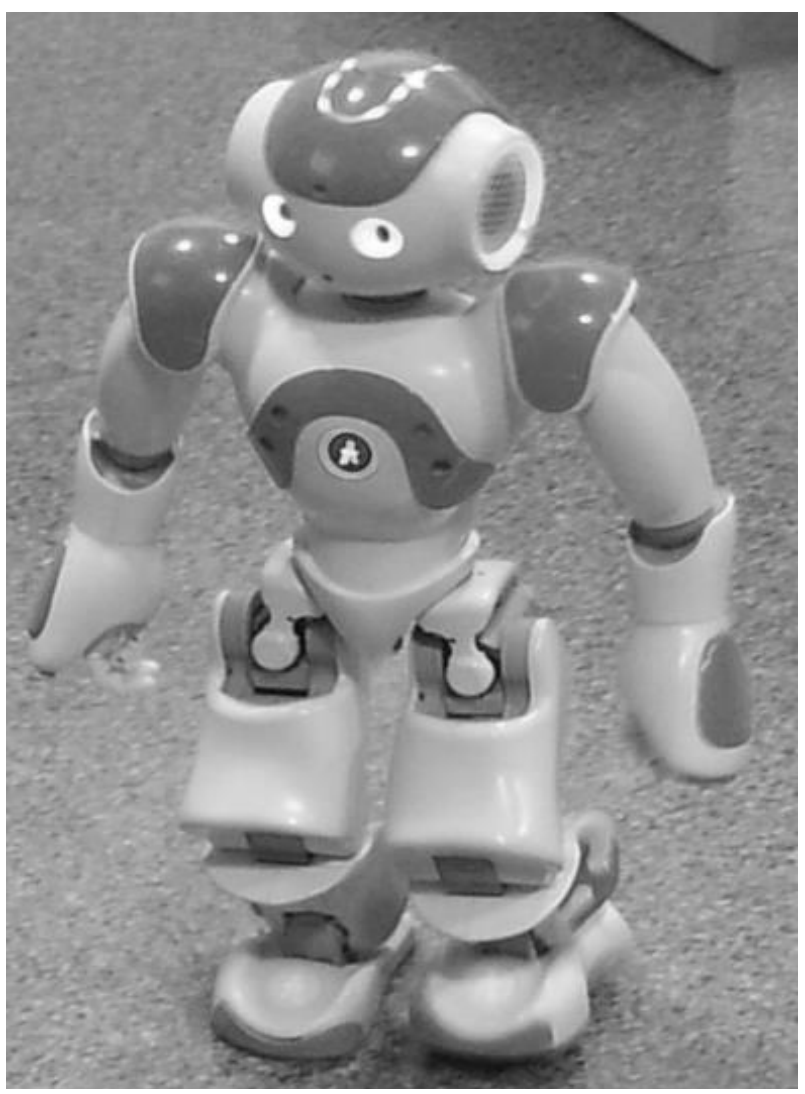

Fig 4. Nano Robot 
Back in the real world, Cognitive Robotics can be defines as the science: "concerned with endowing a robot with intelligent behaviour by providing it with a processing architecture that will allow it to learn and reason about how to behave in response to complex goals in a complex world" [14]. Some robots can now interact socially and Kismet, a robot at M.I.T.'s Artificial Intelligence Lab, can recognise human body language and voice inflection and respond appropriately [15]. Common industrial robots, however, are generally rigid devices limited to manufacturing and tasks like welding car components without direct human intervention. They do, however, need a human technician to monitor their workings. While robots like these could be said to have a certain level of intelligence, they are certainly not independent of human control.

On the other hand a home robot vacuum cleaner can currently be said to have a degree of independence. To find their way around, some robots take a linear approach to finding the room boundaries and then moving in rows within that space. Others uses an array of sensors to constantly read their surroundings and send back information about where to go next, or make use of a camera to create a reference map for the room. Most can be programmed with a daily schedule function to make the robot do its work at a specified time. While these machines certainly could not be said to act completely independently, we can imaging a time when the robot might be able to sense that a room needs cleaning and then just go about its work without any direct human command [16].

\section{Actor-Network Theory as a Conceptual Lens: People and Things}

Actor-network theory (ANT) has been around since the mid-1980s and was developed by Bruno Latour, Michel Callon and John Law [17-24] in an attempt to give a significant voice to technological artefacts as they considered that both social and technical determinism were flawed. ANT was designed instead to give a sociotechnical account in which neither social nor technical positions are privileged [18, $24]$ and nothing is purely social or purely technical [25]. ANT asserts that the world is full of hybrid entities [26] containing both human and non-human elements. One could question, for instance, which of the contributions to a piece of software are due to some aspect of the computer hardware, compiler or programming language tools and which are the result of human interactions and the particular likes and preferences of the human programmer

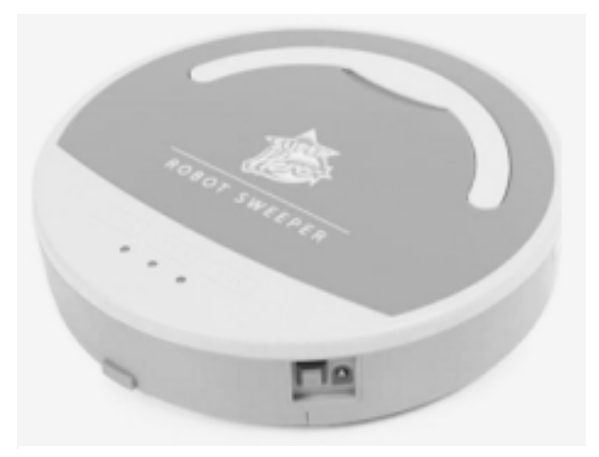

Fig. 5. Robot vacuum cleaner [27]. 
In a simple example, Latour [28] speaks of a device that encourages him to buckle up a car seat belt. First a red light flashes then an alarm sounds at such a high pitch that it is almost impossible to ignore and so he fastens the seat belt. This means that this non-human alarm is able to exert a form of authority over the human driver.

Clearly any consideration of the implications of information technology, the Internet, the Internet of Things and the trend towards machine independence must be a socio-technical one involving both humans and non-humans (Things).

\section{Computers and the Trend towards Machine Independence}

\subsection{Babbage's Difference Engine}

In 1812 the English mathematician Charles Babbage conceived the idea of building a Difference Engine ${ }^{2}$ capable of computing mathematical tables accurately and quickly as a series of arithmetic steps. His aim was to achieve automatic computation by following this set of instructions in which operations were performed in a prescribed order [6]. The Difference Engine definitely required human programming and operation. It did nothing by itself.

\subsection{Early Computing Machines and the First Digital Computers}

Machines such as Vannevar Bush's Differential Analyser, the non-programmable Atanasoff-Berry Computer, Howard Aitken's Harvard Mk 1, Konrad Zuse's Z1, Z2 and Z3 and IBM's Selective Sequence Electronic Calculator also all required considerable human operational control and human maintenance.

The first machines that we might now call computers: Colossus and ENIAC were built essentially as large calculators. Colossus was designed to perform calculations relating to breaking enemy secret codes and ENIAC to calculating ballistic trajectories [6]. They were far from independent machines requiring generated electrical power, constant human operation and control as well as human maintenance in constantly replacing blown radio values.

\subsection{Early Digital Computers}

From the Manchester Baby and other early first generation digital computers such as EDSAC, EDVAC, CSIRAC, UNIVAC-1, LEO 1, Ferranti Mk 1 and IBM 701 whose prime purpose involved calculations, either for scientific, military or business data processing purposes, use of radio valves necessitated the constant presence of a maintenance man.

2 The Difference Engine was never built and was, of course not what we would currently call a computer. Babbage's later Analytical Engine, also although never actually built, would have come closer to this. 
These machines were far from independent in operation and to use one you had to be (almost) a white-coated scientist capable of understanding abstract mathematical concepts. They required, in addition to the maintenance people, a programmer to determine what function the computer was to perform and an operator to enter the programs and the data in batch mode. The later use of transistors and integrated circuits reduced the need for maintenance [6]. Although acting in a way to assist human operations, these machines were also far from independent of human control.

\subsection{More Recent Computers}

From mainframes and minicomputers to microcomputers the need for expert operation, control and maintenance has decreased. There is now much less need for an operator and a maintenance man, and the Microsoft Windows, Apple Macintosh and Android user interfaces have made operation much easier. Modern PCs also have a degree of automation with anti-virus programs automatically checking for viruses and uploading their latest versions without direct human control. Can modern computers act independently though? There is quite a way to go before you could answer 'yes' to this question, but these non-human actors are gaining in strength.

\section{Independence Trends in the History of the Internet and the World Wide Web}

When considering the development of the Internet, Tchalakov and Rogers [29] point out the necessity of taking into account the interplay between networks of people and institutions involved in its development, and how it was about much more than the installation of hardware and software.

Long before the Internet much work had been done on digital telegraph communication by people like Harry Nyquist, Alex Reeves and Claude Shannon. The idea of packet switching, fundamental to the Internet, was first devised by Paul Baran in the early 1960s, and then independently a few years later by Donald Davies [30], clearing the way for digital computer communication and the beginnings of the packet switching networks that we now known collectively as the Internet.

Originating with the US Defense Department's ARPANET, the Internet was developed as a packet-switched network in the early 1970s and from its beginning had elements of independence with each message containing the information to take it to its destination without the need for further human direction. Tchalakov and Rogers [29] note that a significant design issue was "to specify what should be left to each network and what functions should be required of all hosts connected to it". There is no central computer running the Internet and its resources are to be found among thousands of individual computers around the world making it almost beyond possible human control, but this alone does not make it independent.

Human use of the early Internet was far from straightforward for non-technical people as it was entirely text-based and there was a need to have some knowledge of systems and access languages such as UNIX. The Web changed all that by offering a 
graphical interface using hypertext to access Internet files. The original idea for hypertext goes back to 1945 when it was outlined by Vannevar Bush and in the 1960s by Ted Nelson and Douglas Engelbart but became particularly significant in 1989 when Tim Berners-Lee at CERN (European Particle Physics Laboratory) proposed a hypertext development project that eventually became the World Wide Web [31]. The Web was designed to allow pages containing hypertext to be stored in a way that allowed other computers access to these pages, again without direct human involvement.

\section{The Internet of Things}

Radio Frequency Identification (RFID) and Wireless Sensor Networks have been in existence for over two decades, but advances towards full use of the Internet of Things (IoT) offer much more and also pose more social challenges [12]. Put very simply, the Internet of Things (IoT) could be described as technology which connects any physical thing to the Internet in order to exchange information with some other thing [32], and could be seen as " $\ldots$ all about physical items talking to each other" [33: 2].

ANT considers all the various interactions between human and non-human actors: between people and people, people and things, and things and things. In the development of computers and the Internet we have seen a trend from machines that initially required a good deal of interaction with humans, to machines that require less such interaction: a move towards machine independence.

The term Internet of Things was first coined some time ago by Kevin Ashton [34] in the context of supply chain management, but has advanced to cover a wide range of other applications. There are many definitions of the Internet of Things and the CASAGRAS project sees it like this: "A global network infrastructure, linking physical and virtual objects through the exploitation of data capture and communication capabilities ... It will offer specific object-identification, sensor and connection capability as the basis for the development of independent cooperative services and applications. These will be characterised by a high degree of autonomous data capture, event transfer, network connectivity and interoperability." [35:10]. SAP Research adds: "A world where physical objects are seamlessly integrated into the information network, and where the physical objects can become active participants in business processes" [36:12].

One important use of the IoT is in healthcare with the use of RFID in hospitals to track equipment like trolleys, surgical equipment, wheelchairs, infusion pumps and defibrillators [37]. RFID and IoT systems could potentially be integrated into other areas such as bedside applications and monitoring, and then extended into remote monitoring of multi-hospital environments. An article in The Australian newspaper [38] describes a new smart watch, equipped with GPS and activity sensors, designed for monitoring the elderly at home or in aged-care facilities which could also be used in cases where patients tend to 'wander away' [39, 40]. 
Driverless smart trains have been in operation between terminals at Singapore airport now for many years, and an Australian mining company is using smart driverless trucks to transport ore from a remote Western Australian mine to a railway line for shipment to Perth. A modern car has a multitude of computer controlled functions that involve a variety of sensors 'talking' to each other and the controlling computer. These include roll sensors, stability control, brake assist and pre-collision systems, all designed to make the car safer. In many cases these can react autonomously in response to perceived threats [12].

Another example of the IoT aimed at improving home or workplace management is the control of appliances such as heaters, air conditioners, washing machines, dishwashers, refrigerators, ovens and home alarms where this can be done from a distance by the human owner with the aid of a smart phone. Initially these individual 'things' in the house would transmit regular status reports so that relevant humans could take appropriate action such as raising temperatures or activating home alarms. A security system might then determine that no humans are present and turn off lights and air conditioning systems to save money. In a later development, if the home security network with Wi-Fi sensors and cameras connected to the Internet detects movement when no one is supposed to be home, the police could be notified that the home had been invaded and the security network could proceed to lock all the doors [12].

Not all IoT devices are really serious in their application though. In an IEEE article, Amanda Davis [41] describes a video camera system that streams to your mobile phone to let you keep an eye on your cat while you are away, and to talk to it through a two-way audio system. You can also activate a moving laser pointer for your cat to chase to keep it amused until you come home.

\section{The Internet of Things, Machine Independence and Human Issues}

In a fascinating article called: 'Do objects dream of an Internet of things', Teodor Mitew [42] describes Brad the Toaster which is part of the 'Addicted Products' project by Simone Rebaudengo and Haque Design Research [43]. Addicted Toasters love to be used to make toast and have agency and desires. They get jealous of other toasters that are appreciated more than they. They are connected to each other via the Internet and don't recognise owners as such, but know how their fellow Toasters are getting on. If an Addicted Toaster is not used enough it will try to get itself transported to someone else that makes more toast.

"Brad is a toaster connected to the Internet, and to other toasters like him. He often exchanges information with his fellow toasters, with whom he tweets about the usage habits of their human hosts. He and his fellow toasters are not owned as other, simpler, toasters before them used to be. They are hosted by humans who have promised to use them. He loves being used, and is sensitive to learning that other toasters are used more often than him. When feeling under-appreciated, Brad will draw attention to himself by playing pranks, throwing tantrums, and expressing his 
sadness loudly on Twitter. Eventually, Brad will become disillusioned and demand a move to another, more caring host. He will depart, leaving the smell of burned toast behind him." [42:4]

Independence from direct human control is more apparent in Web applications such as the Amazon website which knows, from your previous purchases, what book you are likely to buy next. Many other applications also remember what you did or what you asked last time. When you logon to you supermarket website to place your grocery order the software knows who you are, what you have purchased in the past, and what you are likely to order this time.

Is it possible to be anonymous anymore? The smart phone that most of us carry is actually also a tracking device. Apart from being able to tell you the location of your nearest restaurant, it can also tell anyone with access to the data it collects where you are at any given moment and where you have been. This has echoes of Big Brother in George Orwell's [44] book 'Nineteen Eighty-Four'. In other cases your email provider will also send you personal advertisements based on the content of your supposedly private messages [12]. In a recent newspaper article in the Sunday Age [45], in relation to Orwell's Big Brother technology, Australian Federal MP Adam Brandt says he doesn't equate surveillance just with use of technology, but sees a difference between sharing and being spied on.

Mitew [42] further describes the potential of IoT embedded objects to completely dispense with humans as intermediaries when they are in each other's interaction range. The expectation is that fridges, cars, coffee cups and, of course toasters "form a contextually rich conversation with no human interference or presence" [42:10] where they are expected to 'socialise' with one another, exchanging data [46]. The IoT, involving sensor input and remote activation of devices, sometimes by other devices, comprises a non-human network where the level of autonomy and decision making by the devices is fundamentally different from anything we have seen before.

Given how many predictions of the future of computing have turned out to be so wrong, it is a brave person who now makes one. Although they may be apocryphal, predictions such as that attributed to Thomas Watson (IBM): "I think there is a world market for maybe five computers", and Bill Gates: "640K ought to be enough for anybody" would discourage any sensible person from such predictions, but we will indulge in some speculations nevertheless. For example, perhaps in the future some of the Things might act autonomously on the basis of their sensors, so doing away with the need for human intervention. It is then perhaps a small step to: "I'm sorry, Dave. I'm afraid I can't do that. ...".

Regarding the medical technology that can be used to measure and keep track of physiological parameters and provide information back to you, it is one thing to do this but quite another to then automatically send this data to your hospital or your local medical General Practitioner. Also the Internet is not without critics as a 2010 article in the Telegraph newspaper by Nicholas Carr [47] notes: "A growing body of scientific evidence suggests that the net, with its constant distractions and interruptions, is turning us into scattered and superficial thinkers".

In relation to motor vehicle technology, roll sensors, stability control, brake assist and pre-collision systems for a car can in some cases react autonomously to perceived 
threats. Also, should driverless cars be able to exceed legal speed limits to keep up with other cars [48]? How would a driverless car make a decision on the choice of whether to risk killing a pedestrian or of colliding headlong into another car? A recent article in the Guardian Weekly [49] points out another issue: that the exponential growth in connected devices "is outstripping our ability to reframe our ethical and legal approaches to computer decisions".

\section{Conclusion}

In this article we have traced how the development of technologies leading to modern computing, the Internet and the Internet of Things points to an increasing trend: a trend towards these machines and devices becoming more independent of human intervention. The Internet of Things could be described as an enabling technology that is unlike any other. As it involves using sensor input for remote activation of devices, sometimes by other devices, the level of autonomy and decision making by these devices is quite different from anything we have seen before. We argue that it is a fundamentally different type of technology that can be seriously compared with the science fiction scenarios involving self-aware artificial intelligences.

Any study of these matters needs to be a socio-technical one, and actor-network theory is thus a useful way to frame it as a socio-technical approach has been found to allow the understanding of technology not possible by failing to 'listen' to the things and to a range of socio-technical actors. The basis of ANT is to consider interactions, relationships and associations between human and non-human actors and to do so in such a way that consideration of one is not privileged over the other. The term nonhuman actor can be applied to many 'things' ranging from organisations (- these are considered as a black box containing human actors) to machines and other items of technology. These interactions can be between people and people, people and things, and things and things. In this paper we have seen a trend from machines that initially required total control by humans to those needing much less such interaction and finally to machines that can operate without direct human control: a move towards machine independence.

We could now question whether people like Stephen Hawking are right to be worried about this trend and whether some of the science fiction scenarios might come true. What will be the future of relationships between humans and machines? It will be interesting to see what the next few years bring!

\section{References}

1. Asimov, I., I, Robot. 1950, New York: Gnome Press.

2. Ambrosetti, N., Wonder, Sorcery and Technology: Contribute to the History of Medieval Robotics, in History of Computing: Learning from the Past, A. Tatnall, Editor. 2010, Springer: Heidelberg, Germany. p. 16-25.

3. Wikipedia, Machine. 2016, July 2016]; Available from: https://en.wikipedia.org/wiki/Machine 
4. Oxford, The Concise Oxford English Dictionary. $11^{\text {th }}$ edition, ed. C. Soanes and A. Stevenson. 2004, Oxford: Oxford University Press.

5. Merriam-Webster. Merriam-Webster Dictionary. 2015 January 2016]; Available from: http://www . merriam-webster.com/dictionary/independent.

6. Tatnall, A., History of Computers: Hardware and Software Development, in Encyclopedia of Life Support Systems 2012, UNESCO - Eolss Publishers Co Ltd: Ramsey, Isle of Man, UK.

7. Al-Jazari, I., The Book of Knowledge of Ingenious Mechanical Devices (Kitab fi ma 'rifat al-hiyal al-handasiyya) 1206, Dordrecht: Reidel (translation published in 1974).

8. Čapek, K., R.U.R. (Rossum's Universal Robots). 1920, Prague: Aventinum.

9. Dick, P.K., Do Androids Dream of Electric Sheep? 1968, New York: Ballantine Books.

10. McCarthy, J., et al., A Proposal for the Dartmouth Summer Research Project on Artificial Intelligence (1955). AI Magazine, 2006. 27(4): p. 12-14.

11. Cellan-Jones, R. Stephen Hawking warns artificial intelligence could end mankind. 2014 October 2015]; 2 December 2014:[Available from: http: //www.bbc.com/news/technology-30290540.

12. Tatnall, A. and B. Davey, The Internet of Things and Beyond: Rise of the Non-Human Actors. International Journal of Actor-Network Theory and Technological Innovation, 2015. 7(4): p. 58-69.

13. Adams, D., The Hitch-Hikers Guide to the Galaxy. 1979, London: Pan Books.

14. Wikipedia. Cognitive Robotics. [Web] 2015 January 2016]; Available from: https://en.wikipedia.org/wiki/Cognitive_robotics.

15. Harris, T. How Robots Work. 2015 January 2016]; Available from: http://science. howstuffworks. com/robot6.htm.

16. Miele. Robot Vacuum Cleaner. 2016 January 2016]; Available from: http://www.miele.com.au/domestic/robot-vacuum-cleaner$2750 . \mathrm{htm}$.

17. Callon, M., Some Elements of a Sociology of Translation: Domestication of the Scallops and the Fishermen of St Brieuc Bay, in Power, Action \& Belief. A New Sociology of Knowledge?, J. Law, Editor. 1986, Routledge \& Kegan Paul: London. p. 196-229.

18. Callon, M. and B. Latour, Unscrewing the Big Leviathan: how actors macro-structure reality and how sociologists help them to do so, in Advances in social theory and methodology. Toward an integration of micro and macro-sociologies, K. Knorr-Cetina and A.V. Cicourel, Editors. 1981, Routledge \& Kegan Paul: London. p. 277-303.

19. Latour, B., The Prince for Machines as well as for Machinations, in Technology and Social Process, B. Elliott, Editor. 1988, Edinburgh University Press: Edinburgh. p. 20-43.

20. Latour, B., The Powers of Association, in Power, Action and Belief. A New Sociology of Knowledge? Sociological Review monograph 32, J. Law, Editor. 1986, Routledge \& Kegan Paul: London. p. 264-280.

21. Latour, B., Aramis or the Love of Technology. 1996, Cambridge, Ma: Harvard University Press.

22. Law, J., On the Social Explanation of Technical Change: The Case of the Portuguese Maritime Expansion. Technology and Culture, 1987. 28(2): p. 227-252.

23. Law, J., ed. A Sociology of Monsters. Essays on Power, Technology and Domination. 1991, Routledge: London. 
24. Law, J. and M. Callon, The Life and Death of an Aircraft: A Network Analysis of Technical Change, in Shaping Technology/Building Society: Studies in Sociological Change, W. Bijker and J. Law, Editors. 1992, MIT Press: Cambridge, Ma. p. 21-52.

25. Law, J., Introduction: monsters, machines and sociotechnical relations, in A Sociology of Monsters: Essays on Power, Technology and Domination, J. Law, Editor. 1991, Routledge: London.

26. Latour, B., We Have Never Been Modern. 1993, Cambridge, MA: Harvester University Press.

27. Tatnall, A., Actor-Network Theory as a Socio-Technical Approach to Information Systems Research, in Socio-Technical and Human Cognition Elements of Information Systems, S. Clarke, et al., Editors. 2003, Information Science Publishing: Hershey, PA. p. 266-283.

28. Latour, B., Where are the missing masses? The Sociology of a Few Mundane Artifacts, in Shaping Technology/Building Society: Studies in Sociological Change, W. Bijker and J. Law, Editors. 1992, MIT Press: Cambridge, Ma.

29. Tchalakov, I. and J.D. Rogers, Computer Networks as the Embodiment of Social Networks: The Role of National Scientific Communities in the Development of Internet in the U.S. and Bulgaria. International Journal of Actor-Network Theory and Technological Innovation, 2014. 6(3): p. 1-25.

30. Wheen, A., Dot-Dash to Dot.Com - How Modern Telecommunications Evolved from the Telegraph to the Internet. 2011, Chichester, UK: Springer.

31. Davison, A., S. Burgess, and A. Tatnall, Internet Technologies and Business. 3rd ed. 2008, Melbourne: Data Publishing.

32. Colitti, W., et al., Embedded Web Technologies for the Internet of Things, in Internet of Things: Challenges and Opportunities, S.C. Mukhopadhyay, Editor. 2014, Springer: Heidelberg, Germany. p. 55-74.

33. Mukhopadhyay, S.C. and N.K. Suryadevara, Internet of Things: Challenges and Opportunities, in Internet of Things: Challenges and Opportunities, S.C. Mukhopadhyay, Editor. 2014, Springer: Heidelberg, Germany. p. 1-17.

34. Ashton, K., That “Internet of Things"' thing. RFID Journal 1999(22 June 1999).

35. CASAGRAS. CASAGRAS Final Report: RFID and the Inclusive Model for the Internet of Things. 2014 October 2015]; Available from: https: / / docbox.etsi.org / zArchive/TISPAN/Open/IoT/low\%20resolution/www.rfidglobal .eu\% 20CASAGRAS20IOT20Final\%20Report\%2010w20resolution.pdf

36. Haller, S., Internet of Things: An Integral Part of the Future Internet. 2009, SAP Research: Prague.

37. Unnithan, C., Examining Innovation Translation of RFID Technology in Australian Hospitals through a Lens Informed by Actor-Network Theory, in Information Systems. 2014, Victoria University: Melbourne, Australia.

38. Foreshew, J., Watch watches out for the aged, in The Australian 2015, News Media: Melbourne.

39. Unnithan, C., et al. RFID translation into Australian Hospitals: An exploration through Actor-Network Theoretical Lens. in Proceedings of the International Conference on Information Society (i-society 2013). 2013. Toronto: University of Toronto, Canada.

40. Unnithan, C. and A. Tatnall, Actor-Network Theory (ANT) based visualisation of SocioTechnical Facets of RFID Technology Translation: An Australian Hospital Scenario. 
International Journal of Actor-Network Theory and Technological Innovation, 2014. 6(1): p. 31-53.

41. Davis, A. Boost Your Home's IQ With These Seven Gadgets. 2015 January 2016];

Available from: http://theinstitute.ieee.org/technology-

focus/technology-topic/boosting-your-homes-iq-with-these-

seven-gadgets.

42. Mitew, T., Do objects dream of an Internet of things? . The Fibreculture Journal, 2014. 2014(23): p. 1-25.

43. Rebaudengo, S. Addicted Toasters 2012 January 2016]; Available from: http://www.haque.co.uk/addictedtoasters.php.

44. Orwell, G., Nineteeen Eighty-Four. 1949, Great Britain: Martin Secker \& Warburg.

45. Elder, J., Everyone is Watching, in Sunday Age. 2015, Fairfax: Melbourne. p. 16.

46. Yan, L., et al., The Internet of Things: From RFID to the NextGeneration Pervasive Networked Systems. 2008, New York: Auerbach Publications.

47. Carr, N., How the Internet is making us stupid, in The Telegraph. 2010.

48. O'Callaghan, J., Google's driverless cars will EXCEED legal speed limits so they can keep up with other drivers, in DailyMail 2014.

49. Arthur, C., What next in robot revolution?, in The Guardian Weekly. 2016: London. 